\section{Doi: $10.15863 /$ TAS \\ International Scientific Journal Theoretical \& Applied Science}

p-ISSN: 2308-4944 (print) e-ISSN: 2409-0085 (online)

Year: $2014 \quad$ Issue: 12 Volume: 20

Published: $30.12 .2014 \quad$ http://www.T-Science.org
Natalia Nikolaevna Kulikova Candidate of Economic Sciences,

Associate professor,

Department of Marketing and Commerce,

Moscow state University of instrument engineering and Informatics, Moscow, Russia karpuxinanatasha@yandex.ru

SECTION 31. Economic research, finance, innovation, risk management.

\title{
THE PRINCIPLES OF INTERACTION BETWEEN THE ACTORS OF THE INNOVATION CHAIN IN THE ELECTRONICS INDUSTRY
}

Abstract: Realization of activity of subjects of electronic industry isn't possible on linear model today. The new infrastructure of branch of microelectronics defines formation of the new principles according to which interaction and development of participants of an innovative chain is carried out.

Key words: innovations, principles of interaction, participants of an innovative chain.

Language: Russian

Citation: Kulikova NN (2014) THE PRINCIPLES OF INTERACTION BETWEEN THE ACTORS OF THE INNOVATION CHAIN IN THE ELECTRONICS INDUSTRY. ISJ Theoretical \& Applied Science 12 (20): 37-41. doi: http://dx.doi.org/10.15863/TAS.2014.12.20.9

\section{ПРИНЦИПЫ ВЗАИМОДЕЙСТВИЯ СУБЪЕКТОВ ИННОВАЦИОННОЙ ЦЕПОЧКИ В ЭЛЕКТРОННОЙ ПРОМЫШЛЕННОСТИ}

Аннотация: Реализация деятельности субъектов электронной промышленности сегодня не возможна по линейной модели. Новая инфраструктура отрасли микроэлектроники определяет формирование новых принципов, в соответствии с которыми осуществляется взаимодействие и развитие участников инновационной цепочки.

Ключевые слова: инновацчии, принциипы взаимодействия, участники инновационной цепочки.

Сегодня приоритетным является направление развития страны на основе активизации инновационной области базовых наукоемких отраслей народного хозяйства. Базовой отраслью для всех сфер экономики страны является электронная промышленность, наиболее наукоемкой и технологически сложной отраслью которой выступает микроэлектроника.

В отрасли микроэлектроники сегодня сформировалась новая инфраструктура, включающая следующих участников [1]: дизайн-центры общего назначения, специализированные дизайн-центры, фабрикифаундри, фаблесс-компании, испытательные центры и фабрики по сборке электронных компонентов.

Новая инфраструктура отрасли не позволяет организовать все этапы инновационной цепочки на одном предприятии. Отдельный экономический субъект микроэлектроники сегодня должен быть лучшим в конкретном направлении, а для реализации инновационной цепочки поддерживать отношения с предприятиями, реализующими другие этапы проектирования и разработки микроэлектронных компонентов.

Новые условия хозяйствования сегодня отменили единый хозяйственный комплекс, реализованный по принципу «единой фабрики». Только за счет соединения усилий всех участников инновационной цепочки, их ресурсов возможно проектирование и разработка микроэлектронных компонентов.

Каждый из участников новой инфраструктуры выполняет свои определенные функции (табл. 1).

Организация

взаимодействия профессиональных участников российского рынка микроэлектроники представлена несколькими моделями [1]: взаимодействие «заказчик - дизайн-центры - фабрики-фаундри» и взаимодействие «фаблесс-компании фабрики-фаундри». Выбор модели определен 
наличием заказчика или потребителя изделия: выполняется разработка на заказ или на основе анализа рыночного спроса.
Bce участники для создания инновационной цепочки должны иметь ресурсы, технологии и мощности (табл. 2).

Таблица 1

Функции участников инновационной цепочки отрасли микроэлектроники

\begin{tabular}{|c|c|}
\hline $\begin{array}{c}\text { Участник инновационной } \\
\text { цепочки }\end{array}$ & Функции участника \\
\hline Дизайн-центр общего назначения & Весь цикл проектирования изделия и подготовка к производству \\
\hline $\begin{array}{l}\text { Специализированный д дизайн- } \\
\text { центр }\end{array}$ & Разработка документации на специализированные блоки изделия \\
\hline Фаблесс-компания & $\begin{array}{l}\text { Весь жизненный цикл изделия, за исключением изготовления и } \\
\text { испытаний }\end{array}$ \\
\hline Фабрика-фаундри & Изготовление кристаллов электронных компонентов \\
\hline Испытательный центр & Проведение испытаний электронных компонентов \\
\hline $\begin{array}{l}\text { Фабрика по сборке электронных } \\
\text { компонентов }\end{array}$ & Сборка электронных компонентов (корпусирование) \\
\hline
\end{tabular}

Таблица 2

Необходимые ресурсы, технологии и мощности участников инновационной цепочки отрасли микроэлектроники

\begin{tabular}{|c|c|}
\hline $\begin{array}{c}\text { Участник инновационной } \\
\text { цепочки }\end{array}$ & Ресурсы, технологии и мощности участника \\
\hline $\begin{array}{l}\text { Дизайн-центр } \quad \text { общего } \\
\text { назначения }\end{array}$ & $\begin{array}{l}\text { - } \text { современная компьютерная техника и специализированное ПО; } \\
\text { - } \text { узкоспециализированный квалифицированный персонал. }\end{array}$ \\
\hline $\begin{array}{l}\text { Специализированный дизайн- } \\
\text { центр }\end{array}$ & $\begin{array}{l}\text { - современная компьютерная техника и специализированное ПО; } \\
\text { - } \text { узкоспециализированный квалифицированный персонал. }\end{array}$ \\
\hline Фаблесс-компания & $\begin{array}{l}\text { - } \quad \text { современная компьютерная техника и специализированное ПО; } \\
\text { - } \text { узкоспециализированный квалифицированный персонал. }\end{array}$ \\
\hline Фабрика-фаундри & $\begin{array}{ll}\text { - } & \text { технологические мощности для изготовления изделий; } \\
- & \text { материалы; } \\
- & \text { узкоспециализированный квалифицированный персонал. }\end{array}$ \\
\hline Испытательный центр & $\begin{array}{l}\text { - } \text { специализированное оборудование для тестирования изделий; } \\
\text { - } \text { узкоспециализированный квалифицированный персонал. }\end{array}$ \\
\hline $\begin{array}{l}\text { Фабрика по сборке электронных } \\
\text { компонентов }\end{array}$ & $\begin{array}{l}\text { - специализированное оборудование для корпусирования } \\
\text { изделий; } \\
\text { - узкоспециализированный квалифицированный персонал. }\end{array}$ \\
\hline
\end{tabular}

Взаимодействие

инновационной цепочки - это согласованная деятельность. При организации взаимодействия и координации деятельности все участники инновационной цепочки должны руководствоваться общими, исходными положениями (принципами).

Для всех участников инновационной цепочки характерны взаимодействие и развитие, необходимые для взаимного влияния друг на друга. Взаимодействие и развитие неразделимы: взаимодействие возможно только на основе развития, а развитие реализуется путем эффективного взаимодействия участников. Поэтому фундаментальным принципом в организации взаимоотношений субъектов инновационной цепочки отрасли микроэлектроники является принцип взаимодействия и развития, который проявляется в целостности, структурном разнообразии, эффективном развитии и формировании нового.

Используя системный и кибернетический подходы произведем конкретизацию принципа взаимодействия и развития участников инновационной цепочки в отрасли микроэлектроники.

1. Принции обязательного контрактного взаимодействия хотя бы с одним участником инновационной цепочки. Участие субъектов в инновационной цепочке обусловлено множеством связей и организационноэкономическими отношениями с другими
ISPC European Research, Birmingham, United Kingdom 
участниками, что приводит к формированию новшеств.

Поэтому контрактное взаимодействие субъектов инновационной цепочки долгосрочную мотивацию при взаимодействии субъектов инновационной цепочки. За счет контрактного взаимодействия определяется место каждого участника в инновационной цепочке и принципы взаимодействия. Реализации контрактной формы взаимодействия субъектов обеспечивает реализацию инновационной цепочки и практическую состоятельность инноваций. [2]

2. Принции наличия главного субъекта в инновационной цеепочке. Главным субъектом в инновационной цепочки выступает участник, выделяющий ресурсы на проектирование и разработку электронных компонентов и отвечающий за результативность инновационной деятельности. Будущее инновационной цепочки определяется в основном уровнем развития главного субъекта.

3 Принциип ответственности за результаты инновационной деятельности. За счет того, что каждый субъект инновационной цепочки выполняет определенные функции, так или иначе связанные с выходом инновационного потока, права на результаты инновационной деятельности определяются контрактными отношениями.

4. Принциип понимания всеми участниками роли в инноващчионой цุепочке. Всех участников инновационной цепочки сегодня подразделяют на три вида [3, 5]:

1. специализированные субъекты, создающие и реализующие инновационную деятельность - юридические и физические лица, основная деятельность которых связана с созданием и передачей инноваций в различные сферы производства и управления общественными процессами;

2. субъекты, обеспечивающие функционирование и развитие специализированных субъектов инновационной деятельности - юридические и физические лица, оказывающие услуги субъектам инновационной деятельности (финансовые, информационные, маркетинговые, лизинговые и прочие услуги).

3. субъекты, регулирующие и обеспечивающие условия инновационной деятельности - органы государственной власти, которые обеспечивают установление общих направлений и принципов развития инновационной деятельности, утверждают инновационные проекты, программы и формы государственной отчетности, а также регистрируют субъектов, реализующих инновационные проекты.

Роль каждого участника в инновационной цепочке определяется функциями, а также ресурсами и средствами необходимыми для проектирования и разработки электронных компонентов.

5. Принцип ответственности всех участников инновационной цепочки. Взаимная обусловленность деятельности субъектов инновационной цепочки определяет необходимость согласования решаемых ими задач. Поэтому ответственность за эффективную реализацию всех этапов инновационной цепочки должна осознаваться всеми субъектами. За счет эффективного выполнения своих функций каждый участник цепочки получает экономическую и социальную выгоду.

Ответственность

участников инновационной цепочки определяется функциональными связями, организационноэкономическими отношениями, социальноэкономическими отношениями, через согласование действий, согласование взаимодействий и согласование интересов.

6. Принцип взаимозависимости участников инновационной цеепочки. Каждый участник инновационный цепочки взаимозависим от других участников. В создании новых знаний, являющихся сетевым ресурсом, и их использовании заинтересованы все участники инновационной цепочки. Взаимодействие участников инновационной цепочки должно рассматриваться как общее движение сгруппированных субъектов вперед в одном направлении. Между участниками инновационной цепочки существует технологическая взаимозависимость.

В инновационной цепочке не должны возникать разрывы и простои. Поэтому инновационный процесс сегодня реализуется на основе замкнутого цикла, а также взаимовыгодного партнерства.

7. Принцип наличия обратных связей. Обратная связь представлена знаниями о результатах деятельности на каждом этапе инновационного цепочки. За счет реализации данного принципа возможно создание товара, как объекта интеллектуальной собственности, и обеспечение развития всех субъектов инновационной цепочки.

8. Принции участия одного субъекта в нескольких инновационных цепочках. В успешном получении инновации заинтересованы все участники инновационной цепочки, реализующие свои частные интересы. 
Причем конкретный субъект может быть участником нескольких цепочек. Состав и порядок формирования цепочки участников определяется инновационным проектом.

Инновационные цепочки в микроэлектроники формируются исходя из преобладания вертикальных потоков информации, ведомственной замкнутости, требований по обеспечению конкурентоспособности и экономической эффективности результатов, целесообразности и рационального взаимодействия участников, на основе интенсивной динамики структуры рынков. Инновационные цепочки в микроэлектроники определяются региональными, межрегиональными, национальными процессами. Такие цепочки сегодня характеризую распределение производительных сил. Любая инновационная цепочка является частью инновационной инфраструктуры.

\section{9. Принщип эффективной} востребованности инновационных проектов. Реализация инновационных проектов осуществляет эффективный перевод результатов проектирования и разработок в коммерческие результаты. Недостаточная востребованность инновационных проектов в микроэлектроники может быть обусловлена недостатком средств у субъектов на модернизация из-за невысокой эффективности производственно-хозяйственной деятельности, а также технологическим отставанием от конкурентов.

При оценке эффективной востребованности проекта результат проекта должен рассматриваться как товар. Поэтому необходимо дать маркетинговое обоснование проекта, определить структуру финансирования и финансовые показатели проекта и обязательно произвести идентификацию рисков проекта. [7]
10. Принщип наличия высокоэффективной системы информационного обмена между субъектами инновачионной иепочки. За счет систем информационного обмена участники инновационной цепочки реализуют контролирующие и сопровождающие процессы проектирования и разработки электронных компонентов, а также на их основе осуществляется коорднация их непосредственного взаимодействия.

Разработка эффективного информационного обеспечения процессов инновационной цепочки позволяет существенно снизить уровень общих издержек и добиться нового качества электронных компонентов. Одним из главных факторов эффективности информационного обеспечения процессов инновационной цепочки является взаимодействие информационных систем всех субъектов инновационной цепочки и формирование массивов интегральной информации на всех этапах проектирования и разработки электронных компонентов, то есть формирование единого информационнотехнологического пространства инновационной цепочки проектирования и разработки электронных компонентов.

Представленные

принципы взаимодействия субъектов инновационной цепочки рынка микроэлектроники в силу своей значимости должны выступать ориентиром при организации и осуществлении делового сотрудничества. Принципы являются основой ускорения темпов и повышения эффективности инновационной деятельности дизайн-центров общего назначения, специализированных дизайн-центров, фабрик-фаундри, фаблесскомпаний, испытательных центров и фабрик по сборке электронных компонентов.

\section{References:}

1. Kulikova NN/Karpukhina NN/ (2013) Modeli razvitija jelektronnoj promyshlennosti. Rossijskoe predprinimatel'stvo. No. 10 (232). pp.149-157. Available:

http://www.creativeconomy.ru/articles/28913/ (Accessed: 22.12.2014).

2. Grishhenkov AI (2011) Struktura kontraktnyh vzaimodejstvij sub'ektov innovacionnoj seti. Kreativnaja jekonomika. No. 5 (53). pp. 65-70. Available:

http://www.creativeconomy.ru/articles/3410/ (Accessed: 22.12.2014).
3. Karro II, Anpilogova ME (2014) Uchastniki innovacionnogo processa i formy ih vzaimodejstvija. Materialy V Mezhdunarodnoj studencheskoj jelektronnoj nauchnoj konferencii «Studencheskij nauchnyj forum». Available:

http://www.scienceforum.ru/2013/74/4619 (Accessed: 22.12.2014).

4. Barinov VA, Zhmurov DA (2007) Razvitie setevyh formirovanij $\mathrm{V}$ innovacionnoj jekonomike. Menedzhment v Rossii i za rubezhom. No. 1. 
5. Kotel'nikov V (2014) Novye principy menedzhmenta $\mathrm{V}$ sovremennoj bystro menjajushhejsja jekonomike, dvizhimoj innovacijami. Available: http://www.cecsi.ru/coach/innovation_systemic. html (Accessed: 22.12.2014).

6. Bykovskij VV, Mishhenko ES, Bykovskaja EV and etc. (2011) Upravlenie innovacionnymi proektami i programmami: uchebnoe posobie. Tambov: Izd-vo GOU VPO TGTU, pp. 104.

7. Kokueva JA (2007) Metodika otbora malyh innovacionnyh predprijatij dlja poluchenija investicionnyh l'got. Problemy sovremennoj jekonomiki. No. 4 (24). Available: http://www.meconomy.ru/art.php?nArtId=1726 (Accessed: 22.12.2014).

8. Davydenko AS (2009) Postroenie sistemy korporativnogo upravlenija innovacionnoj dejatel'nost'ju v vysokotehnologichnyh otrasljah promyshlennosti: Avtoref. dis. ... doktora jekon. nauk: 08.00.05. Davydenko Aleksandr Sergeevich; Institute mezhdunarodnogo prava i jekonomiki imeni A. S. Griboedova. - Moscow. pp. 48.

9. Arskij JM (2007) Informacionnye resursy dlja podderzhki innovacij / JM Arskij, VA Cvetkova, SP Jashukova // Informacionnye resursy Rossii. No. 6. pp. 32-36. Available: http://www.aselibrary.ru/digital resources/journ al/irr/2007/number 6/number 6 4/number 64 734/ (Accessed: 22.12.2014).

10. Krjukova AA (2012) Upravlenie innovacionnoj dejatel'nost'ju. Konspekt lekcij. - Samara.: FGOBUVPO PGUTI, 2012. pp. 118. 